\title{
O PRONOME ELE ACUSATIVO NA HISTÓRIA DO PORTUGUÊS
}

\author{
Elizane de Soura Teles Silva* \\ Jorge Augusto Alves da Silva**
}

RESUMO: Neste artigo investigamos as estratégias de preenchimento do objeto direto anafórico em Vitória da Conquista, particularmente, acerca da história do Pronome ele acusativo no vernáculo português, com base na Sociolinguística Variacionista, em consonância com a Sócio-história. Nesse sentido, objetivamos: (i) reconstruir a história do Pronome ele acusativo no Português do Brasil, estabelecendo uma comparação entre as normas popular e culta; e (ii) constatar a coexistência do Pronome ele acusativo em concorrência com o clítico acusativo, no recorte dos corpora selecionados. Os dados para análise foram extraídos dos corpora do Português Popular e Culto de Vitória da Conquista, estratificados em sexo e faixa etária, e submetidos ao Programa GoldV arb X. Os resultados revelam que o uso do Pronome ele acusativo tende a ser mais frequente em contextos linguísticos cujo antecedente do objeto apresente o traço semântico [+humano] tanto entre os falantes da norma popular como da norma culta.

PALAVRAS-CHAVE: Acusativo anafórico; Pronome ele acusativo; Português culto e popular; Sociolinguística.

\section{Introdução}

Neste artigo fazemos uma revisão sobre o "pronome ele/ela" na função de acusativo (o ele acusativo) na História da Língua Portuguesa do Brasil, também denominado "pronome lexical ele" (considerando suas flexões). A escolha do tema deu-se

\footnotetext{
* Mestre em Linguística pela Universidade Estadual do Sudoeste da Bahia (Uesb). Coordenadora de Inovação, ligada à PPG e ao Nit/Uesb.

${ }^{*}$ Professor Pleno da Universidade Estadual do Sudoeste da Bahia (Uesb). Doutor em Letras (Linguística Histórica) pela Universidade Federal da Bahia (Ufba).
} 
graças à constatação de que o uso do pronome ele na função de acusativo remetia aos usos populares atávicos, ou seja, à língua dos primeiros lusitanos e que permaneceria vivo no Brasil, expandindo-se para os falantes cultos.

Tais razões levaram-nos a controlar o "ele acusativo" e a descrever do ponto de vista sócio-histórico o seu percurso na histórica da Língua Portuguesa, tendo como base os corpora do Português Popular e do Português Culto de Vitória da Conquista - BA.

Vale lembrar que, com base nos elementos sócio-históricos, as duas variantes do Português Brasileiro foram instituídas a partir de relações sociais desiguais entre dominador e dominado. De um lado temos o Português Culto Brasileiro que se definiu a partir das práticas sociais de uma elite relativamente pequena e de outro o estabelecimento do Português Popular Brasileiro, caracterizado, principalmente, pelas influências de um período histórico marcado pelo multilinguismo das classes subordinadas. Assim, podemos inferir que o Português Culto Brasileiro estabeleceu-se como a variante falada por falantes escolarizados, ou com um número considerável de anos de escolaridade, que se diferenciam pelo domínio dos padrões linguísticos prestigiados pela elite europeia (norma culta), enquanto os falantes do Português Popular Brasileiro se distinguem pela escassez de letramento ou, até mesmo, a falta dele.

Para uma análise empírica dos dados linguísticos, utilizamos como suporte teóricometodológico a Teoria Variacionista Quantitativa (LABOV, 1972), em consonância com os fundamentos da Sócio-história (ROMAINE, 1982), com o intuito de demonstrar que nada na língua é por acaso e tanto a variação quanto a mudança, inerentes aos sistemas linguísticos, estão condicionados por grupos de fatores linguísticos e extralinguísticos.

Nesse intuito, objetivamos reconstruir a história do Pronome ele acusativo no Português do Brasil, estabelecendo uma comparação entre as normas popular e culta.

Iniciamos nossa discussão sobre o fenômeno lançando mão de dois textos basilares para nosso estudo: as ponderações feitas por Herbert Palhano (1958) e por Joaquim Mattoso Câmara Júnior (1970). A primeira obra foi produzida à égide do "evolucionismo linguístico" a qual previa que cada estado de língua (état de langue) seria um degrau na 
evolução das línguas em rumo à simplificação. O segundo texto origina-se de uma análise estruturalista feita por Câmara Junior, que, do ponto de vista geográfico e histórico, trata do uso do pronome ele (ele acusativo) com base em textos de diversos períodos de nossa história linguística.

Partindo desses dois textos, vejamos a seguir a deturpação popular associada ao ele acusativo e, em seguida, a sua origem controversa. Nas subseções seguintes, fizemos um percurso do ele acusativo, desde o Latim ao Português Arcaico. E logo depois, mostramos como o quadro pronominal se reconfigurou, apoiando-nos nas gramáticas latinas e normativas, e a visão do fenômeno pelas gramáticas descritivas. Por fim, fazemos a análise dos dados e as considerações finais, com base nos estudos realizados por nossos contemporâneos.

\section{O ele acusativo: uma "deturpação" popular}

O uso do ele acusativo na Língua Portuguesa esteve, por diversas vezes, associado ao uso estritamente popular (num sentido pejorativo, quando popular opunha-se ao clássico literário ou ao estilo formal e cuidado). Mesmo no campo da literatura canônica, as ocorrências do ele acusativo estão ligadas à norma popular e ao povo, como no seguinte exemplo de Machado de Assis, em que se reproduz a fala de um escravo liberto falando sobre outro escravo. Brás Cubas (personagem que dá nome à obra de Machado de Assis) faz-lhe uma pergunta à qual o liberto responde nos seguintes termos: “[...] - Fez-te alguma coisa? - É um vadio e um bêbado muito grande. Ainda hoje deixei 'ele' na quitanda, enquanto eu ia lá embaixo na cidade, e ele deixou a quitanda para ir na venda beber" (ASSIS, 2010, p. 95, grifo nosso).

Do trecho tirado de Memórias Póstumas de Brás Cubas, identificamos claramente o fenômeno linguístico inerente à variante do Português Popular do Brasil: o ele acusativo.

Passemos a analisar o fenômeno com base em Palhano. Filólogo reconhecido e com amplo conhecimento de lexicologia, Palhano (1958, p. 7) propõe-se a discutir a língua de “nosso povo”, “a fala popular, deixando fora de cogitação os acidentes da linguagem desta 
ou daquela região", ou seja, não se trata de um estudo dialetológico, mas enseja dar conta de uma língua popular geral. Palhano (1958) opõe a língua popular à língua literária e acrescenta que “[...] língua literária e língua popular coexistem sempre sob um nome comum [...]" (PALHANO, 1958, p. 13).

Embora Palhano (1958) afirme que a evolução é um curso natural à língua falada, língua viva, oposta à língua literária (língua cerceada pela tradição gramatical), refere-se à variedade popular a ser descrita como uma deturpação, como demonstra o seguinte trecho em que o autor opina sobre a propagação de uma variante popular nos meios "não-populares", ao afirmar que:

Quando o indivíduo "malfalante" granjeou certo prestígio no seio do grupo a que se vinculou, então irradia sua influência sobre os demais, legando-lhes todas as "deturpações" linguísticas que involuntária e inconscientemente perpetrou. (PALHANO, 1958, p. 35, grifo nosso). ${ }^{1}$

Neste caso, conforme Palhano (1958), a ação do povo sobre a língua teria alterado a relação dos pronomes pessoais com os seus referentes discursivos; destarte, a língua popular careceria da gradação das pessoas a qual teria sido mantida na literatura. Além dessa perda de gradação, observou também o uso do pronome reto com preposições (“entre eu e tu") e da mesma sorte a existência de construção como "vi ele/ela", em contraponto ao "vi-o/a" (PALHANO, 1958, p. 43-44).

Tido por solecismo (ALMEIDA, 2001), isto é, vício de linguagem (erro de sintaxe) só é tolerado quando for feito com “intenção estilística” (CAMARA JR, 1984, p. 224). Câmara Jr, eminente linguista do século XX, reconhece o ele acusativo como um “[...] dos traços característicos do português do Brasil" (CÂMARA Jr, 1984, p. 47). No entanto, mesmo reconhecendo que é um linguajar muito brasileiro, não se exime de aplicar censura

${ }^{1}$ A observação feita por Palhano é pertinente ao fato de em nosso estudo cotejarmos duas normas linguísticas: a culta e a popular. 
ao afirmar que “[...] o ensino escolar o condena, e estamos de acordo em se ver aí um 'erro'.” (CÂMARA JR, 1984, p. 47, grifo nosso).

Se Palhano (1958) retrata o ele acusativo como um traço da língua popular do Brasil, um caso de variação diafásica, Câmara Jr (1972) reconhece nele um caso de variação estilística, em termos sociolinguísticos, ao afirmar que:

É, todavia, um traço geral típico do português oral de todos os níveis sociais no Brasil; só o evitamos em certas situações nas quais aquele que fala sente toda sua responsabilidade de homem instruído e, mesmo assim, ele não chega sempre a eliminá-lo de todo. (CAMARA JR, 1972, p. 48).

A tenaz observação feita pelo preclaro linguista demonstra-nos que: i) O uso de ele acusativo não está restrito às camadas populares; ii) $\mathrm{O}$ uso de ele acusativo está em variação com a forma preconizada pela Tradição Gramatical; iii) $\mathrm{O}$ uso de ele acusativo suscita no utente uma avaliação consciente de adequação estilística ([-formal] vs [+formal]).

Adentrando à questão do uso, agora não mais na língua oral, Câmara Jr (1972) relaciona-o à Língua Pré-clássica ou Arcaica e, para tanto, evoca a autoridade incontestável da Filologia, campo profícuo em que atuou Palhano (1958). Devemos notar que Palhano (1958) não menciona a origem do ele acusativo, limitando-se apenas a determinar-lhe a característica de uso. Seria, pois, o ele acusativo (inexistente em terras lusitanas de hoje) um atavismo como costuma ocorrer em línguas transplantadas? A resposta para tal questão vamos buscá-la em Cândido de Figueiredo (1923).

Cândido de Figueiredo (1923) vai além do solecismo ao classificá-lo como arcaísmo, um atavismo já esquecido em terras lusitanas. Sua manutenção estaria ligada ao povo iletrado que a aprendeu de boca dos primeiros colonizadores e, por questões sociais, conservou-a já que se manteve distante da ação normatizadora da educação formal escolar.

Desse escorço histórico da questão, podemos tirar três conclusões: 
a) O emprego do ele acusativo não é uma inovação da variante brasileira; no entanto, a sua permanência em terras brasileiras e a frequência de uso são traços que podemos relacionar à nossa variante;

b) O emprego do ele acusativo está relacionado aos usos populares (por ser considerado “solecismo"); no entanto, é de emprego comum também em meios não-populares, mas é evitado em situações monitoradas;

c) O emprego do ele acusativo suscita uma reestruturação do quadro dos pronomes pessoais, havendo, portanto, a necessidade de uma nova configuração daquele quadro com base no uso.

Apresentamos, na subseção seguinte, uma discussão a respeito das teorias que tentam explicar a origem do ele acusativo no Português do Brasil.

\section{O ele acusativo: sua origem controversa}

É inegável a existência do ele acusativo na Língua Portuguesa antes de os portugueses chegarem ao Brasil, segundo Câmara Júnior (1957); no entanto, a sobrevivência de tal construção em terras brasileiras e, praticamente sua ausência na variante portuguesa ${ }^{2}$, tem dividido estudiosos quer filólogos quer linguistas. Vamos à controvérsia.

Silvio Elia (1979), ao tratar de características peculiares ao Português do Brasil, mais especificamente ao Português Popular, afirma que se verificam várias situações de simplificação estrutural, oriundas de contatos linguísticos que teriam dado vasão ao surgimento de uma forma considerada por ele semicrioulo. Apoiando-se em nossa história, chega a

${ }^{2}$ Câmara Júnior (1957), em homenagem a André Martinet, redige em francês um esclarecedor capítulo em que reúne evidências da superveniência do ele acusativo no Português Brasileiro, inclusive em sua literatura canônica. 
afirmar que, in terra brasilis, surgiu um semicrioulo ou um crioulo secundário ${ }^{3}$ sem que houvesse um estado de pidgin. Para sustentar sua afirmação, apresenta algumas características morfossintáticas facilmente encontradas em situações de contato linguístico, tais como: a simplificação das flexões verbais e nominais (francamente percebida em semicrioulos de base francesa), a existência de reconfiguração de quadros pronominais, tais como o ele acusativo e o uso do pronome reto como oblíquo e o emprego diversificado de preposições ${ }^{4}$.

Assim posto, a ocorrência do ele acusativo não seria o produto da superveniência de uma característica atávica, mas o resultado da recomposição no quadro de pronomes de nossa língua com base nos elementos da língua lexificadora. Tal fenômeno não se restringiria ao ele acusativo, mas faria brotar um uso inaudito em terras portuguesas: o lhe-acusativo, tal como observou Sebastião da Almeida Dalgado (1998 [1900]) ao tratar do crioulo português de Goa. Dalgado (1998) reconhece que podem ser vistas muitas aproximações fonéticas (como o ieísmo) e lexicais entre o português do Brasil e o português falado em Goa. Segundo ele, o "lhe acusativo" era um traço evidente dessa proximidade, o qual, a nosso juízo, poderia ter surgido por analogia ao "ele acusativo".

Por outro lado, houve voz contrária a essa posição teórica e justamente contra ela levantou-se Sousa da Silveira (1952), em suas clássicas Lições de Português. Para o preclaro filólogo, o uso de ele acusativo era nada mais nada menos do que um arcaísmo, uma das velharias lusitanas, esquecida pela língua de Camões. Segundo Silveira (1952, p.131), não apenas o ele acusativo, mas o "mi" ou o "mim", o "ti" e o "si" poderiam ser usados como

\footnotetext{
${ }^{3}$ Silvio Elia usa a denominação "crioulo secundário" por inspiração de Valkhoff e para o termo "semicrioulo" a inspiração foi de Silva Neto (1986 [1950], p. 97).

${ }^{4}$ O filólogo brasileiro Silveira Bueno em Estudos de Filologia Portuguesa (1967) discute alguns alegados brasileirismos, dentre eles os reconhecidos por Silvio Elia como resultantes do contato. Com exemplos retirados de clássicos portugueses, Silveira Bueno demonstra que podemos encontrar tais fenômenos em Portugal, chegando a afirmar que "fácil, entretanto, será demonstrar-lhes que toda essa novidade não passa de velharias muito portuguesas, heranças religiosamente conservadas pelo povo desde os primeiros tempos do idioma europeu." (BUENO, 1967, p. 210). As afirmações de Bueno são bastante exageradas, pois não levam em conta fatores como a licença poética e a necessidade rítmica, já que a maioria dos exemplos citados é de cunho literário.
} 
acusativo e, para demonstrar o que afirmou, cita dois exemplos extraídos da Crestomatia Arcaica de J. J. Nunes ${ }^{5}$ :

(1) "Quen vus ouve, min ouve” (Apud Nunes, Crest. Arc, 26)

(2) "E Judas dezia a Josef que tomasse ele per servo" (ibid, 94)

Faz eco a essa "lição", Rui Barbosa para quem "Eu vi ele" ou "Eu deixei ele" figuram em "bastantes casos" nos clássicos antigos. A que conclusão chega o autor: essa construção é mera sobrevivência no Brasil de antiga construção lusitana. No entanto, sua superveniência estaria circunscrita aos espaços em que a ação da "urbanitas" (formação de uma sociedade urbana) não se fez plenamente, quer nos rincões quer nos espaços citadinos em que a educação não cumpriu seu papel. Assim dito, não seria de se espantar que o ele acusativo recebesse a alcunha de "solecismo", termo eivado de preconceito, já que figura entre os "vícios de linguagem".

Seria, pois, oportuno conjecturarmos que a forma seria apenas tida como arcaica e, portanto, uma preciosidade na língua, ainda viva em nossa variante; mas, para rejeitar-lhe a vernaculidade por anciania, Câmara Jr (1975 [1957]) pondera que os exemplos retirados de textos arcaicos centram-se em casos raros em que a "ênfase" seria a marca da construção.

Nesse sentido, Câmara Jr (1975 [1957], p.48) vê uma situação de reconstrução do sistema pronominal e, para tanto, postula três possíveis explicações: a) sobrevivência do passado, b) evolução fonética inteiramente mecânica e c) uma extensão analógica. Após apresentar evidências que possam sustentar ou não as postulações, Câmara Jr (1975, p. 48) vai concluir que: “[...] Condições específicas do Português do Brasil favoreceram, pois, uma profunda evolução morfológica, que estava estruturalmente prefigurada no sistema pronominal do português." XXXX (2005) analisou o posicionamento teórico de Câmara Jr sobre

\footnotetext{
${ }^{5}$ Em homenagem ao autor, reproduzimos ipsis litteris sua citação mesmo em afronta à norma NBR NBR 10520 da ABNT.
} 
a formação do Português do Brasil e conclui que o linguista, embora reconheça historicamente o papel dos aloglotas na formação de nosso vernáculo, posiciona-se pela sobreposição do português ao bilinguismo reinante na Colônia e, por fim, reconhece que a variante lusitana e a variante brasileira são diferentes porque são "dois territórios nacionais distintos” (CÂMARA JR, 1979 [1975], p.30) e que o surgimento da “subnorma”, entenda-se, o Português Popular do Brasil, ainda está por se explicar.

Em nota filológica presente no Dicionário Houaiss da Lingua Portuguesa (2000), podemos observar que o uso do ele acusativo é reconhecido como arcaísmo, já que, ouçamos os autores, “[...] aparece, esporadicamente, em textos arcaicos, mormente com valor enfático, na função de objeto direto [...]”, tal como sinalizou Sousa da Silveira (1952). Cotejando os dois testemunhos, podemos verificar que o ele acusativo parece restringir-se à forma estritamente escrita ${ }^{6}$ do Português Arcaico e seu uso estaria ligado a um recurso estilístico: a ênfase. Nesse sentido, somos levados a concordar com a observação feita por XXXX (2005), quando ele apresenta evidências científicas contra os que querem ver nos atavismos lusitanos a origem de fenômenos recorrentes no Português do Brasil.

Em suma, podemos ver que existem duas correntes opostas em relação à origem do uso do ele como acusativo: a primeira relaciona-o ao atavismo lusíada atestável em documentos do Período Arcaico; a segunda que aponta para uma influência de aloglotas na alteração da categoria do pronome ele, que passaria de dativo para acusativo, perdendo a preposição a/para.

\footnotetext{
${ }^{6}$ Pode parecer estranho que se use como corolário a invocação de os textos arcaicos serem escritos, o que seria óbvio já que os testemunhos dos que viveram há séculos não poderiam ser registrados; no entanto, a comparação de textos esclarece tal situação: notoriamente, havia textos que eram escritos para serem lidos em voz alta (tal como as canções e peças teatrais) e outros que poderiam ser lidos, mas sem essa necessidade premente (tais como documentos legais, atas, tratados). Com base nisso, Leite de Vasconcelos (1912) observa que formas podem estar mais próximas do uso popular, justamente em textos destinados à audição do povo iletrado.
} 


\section{O ele acusativo: do Latim ao Português arcaico}

A origem dos pronomes pessoais e mais precisamente do pronome ele é lugar comum na descrição histórica da composição dos quadros pronominais da Língua Portuguesa. Segundo Coutinho (2011, p.253), “[...] de todas as classes de palavras são os pronomes pessoais que mais fielmente guardam os vestígios da declinação latina", ou dizendo melhor, os pronomes tendem a conservar a divisão existente na língua mãe: a) Caso reto $v s$ caso oblíquo; b) Caso reto ocupando a função de sujeito ou predicativo do sujeito; c) Caso oblíquo assumindo as demais funções lógicas; d) Formas especiais para demarcar a diferença entre os casos.

Do ponto de vista histórico, a inexistência de pronomes pessoais de terceira pessoa tornou necessária a "vinda" de outra forma pronominal para preencher essa lacuna. Tal fato fez com que, no Latim Vulgar, os pronomes demonstrativos passassem a ocupar os casos oblíquos. Em seu Compêndio de Gramática Histórica Portuguesa, Nunes (1975 [1910]) destaca que o Latim Vulgar não possuía uma forma específica para o pronome pessoal de terceira pessoa, recorrendo aos demonstrativos latinos hic, iste, ipse, is, idem, ou ille. O demonstrativo ille foi a forma preferencial para o masculino, empregado pelo Latim Vulgar, que representa ele e el, em português; e illa para o feminino, correspondente a "ela". Ambos foram pluralizados na nossa língua com o acréscimo de $-\mathrm{s}$, abandonando o respectivo plural latino, ou melhor, assumindo apenas o plural do acusativo. Nesse sentido, îlle $>$ èle $>$ ele seria a perfeita equação metacrônica que representaria a mudança do pronome latino para o português.

A transformação de um pronome demonstrativo em um pronome pessoal, fato incontestável na mudança do Latim para as línguas românicas, foi marcada por períodos de intersecção entre o novo pronome pessoal e sua antiga função demonstrativa. Tanto em Português como em Espanhol, o ele acusativo pode vir acompanhado da preposição "a" sem ter sua função alterada: é o caso do objeto direto preposicionado. Embora tal fenômeno restrinja-se a verbos especiais, houve muito desdobramento das gramáticas para explicar-lhe a vernaculidade. 
Indo mais adiante na configuração do pronome ele como acusativo, de acordo Said Ali (1964), no período quinhentista, as formas oblíquas tônicas eram utilizadas pelos escritores como “acusativo enfático”, ou seja, para efeito estilístico, salvando-se, portanto, da peja de "solecismo", dispensando a preposição. Os exemplos coligidos por Said Ali (1964) são de prosa, sendo o primeiro da Crônica do Descobrimento e Conquista da Guiné (1453), publicada em Paris em 1841 cujo autor é Gomes Eanes de Zurara; o segundo vem de uma tradução para o português do Santo Graal. Ei-los:

(3) Contando como cativarom ele e os outros oito (Zurara, Guiné 190).

(4) Leixarei elle (Santo Graal, 129).

Podemos assim resumir a opinião dos historiadores da nossa língua sobre a origem do ele acusativo: Said Ali (1964) considera-o de uso enfático; Nunes (1975) considera-o uma imitação ao Espanhol; e Coutinho (2011) considera-o um dos fenômenos decorrentes das alterações de ordem lógica na passagem do Latim para o Português.

Não podemos encerrar essa subseção sem fazermos referência aos dialetólogos brasileiros que se debruçaram sobre o uso do pronome ele acusativo.

Amaral (1920), em seu trabalho sobre o dialeto "caipira", ou melhor, sobre o processo de dialetação portuguesa no interior paulista, comenta que o uso do pronome "ele/ela" como objeto direto já está bastante generalizado nas diversas regiões do nosso país. E, portanto, não se restringiria a um uso local. Mesmo tendo sido utilizado no período anteclássico do português, a sua produção independe de qualquer relação histórica. Além de ser, neste caso, uma realidade pambrasileira e pancrônica, segundo depreendemos da fala de Amaral, estaria ainda o "ele acusativo" ocasionando a perda da vitalidade dos pronomes oblíquos o/a, "aparecendo quase que unicamente em frases já cristalizadas". Tal perda de vitalidade seria resultado também de outras estratégias de representação da forma pronominal átona, inclusive seu apagamento.

Em linha de abordagem semelhante, segundo Marroquim (1934), há uma luta entre a língua culta e o dialeto, embate que se processa no campo da sintaxe, já que na fala do 
povo encontra-se a língua viva, na qual reside a alma e o caráter do idioma, no seu processo de articulação. Analisando A Lingua do Nordeste (Alagoas e Pernambuco), Marroquim (1934) pontua que os pronomes oblíquos “o”, “a”, “os”, “as” desapareceram por completo, e o "lhe" passou a ser empregado também como objeto direto. Por outro lado, o dialetólogo não faz menção explícita ao pronome "ele" como acusativo, apenas apresenta o "lhe" como inovação no quadro dos pronomes pessoais (quando objeto indireto).

Sigamos rumo à história do Português por meio do estudo da tradição greco-latina espelhada em sua gramática ou na gramática elaborada com base em tal tradição.

\section{Reconfiguração do quadro pronominal: do Latim ao Português}

Verificamos que o pronome pessoal de terceira pessoa foi uma criação do Latim Vulgar, pois não existia no Latim Clássico. E, justamente, por ter sido "cunhado" de matéria dos pronomes demonstrativos, fica marcante seu traço anafórico.

À Tradição Gramatical da Língua Portuguesa, calcada em sua origem greco-latina, coube reestruturar a "nova vida" dos pronomes. Passemos a refletir sobre essa questão.

A Moderna Gramática Portuguesa (BECHARA, 2004) e a Nova Gramática do Português Contemporâneo (CUNHA; CINTRA, 1985) não apresentam divergências significativas quanto ao elenco dos pronomes pessoais e a forma de apresentá-los. Rocha Lima (2003), por sua vez, em sua Gramática Normativa da Lingua Portuguesa, incluiu no seu quadro pronominal uma forma diferente para a $2^{\mathrm{a}}$ pessoa do singular e plural, você/vocês. Assim, para a $1^{\mathrm{a}}$ pessoa (eu, nós); $2^{\mathrm{a}}$ pessoa (tu, você, vós, vocês); e $3^{\mathrm{a}}$ pessoa (ele, ela, eles, elas).

No que se refere à função, as formas dos pronomes pessoais podem ser retas ou oblíquas. As retas (ou subjetivas) assumem a função de sujeito da oração, ao passo que as oblíquas (ou objetivas) são empregadas como complemento do verbo. Os pronomes oblíquos possuem formas átonas e tônicas: ao contrário das átonas (formas próprias do objeto direto), as tônicas vêm sempre regidas de preposição, podendo assumir a função de objeto indireto, complemento nominal, agente da passiva, adjunto adverbial e também de objeto 
direto, quando precedido da preposição a (BECHARA, 2004; CUNHA; CINTRA, 1985; ROCHA LIMA, 2003).

Segundo Rocha Lima (2003, p.318), era frequente o uso das formas tônicas do objeto indireto em função objetiva direta, na linguagem arcaica: "Manda teu mensageiro do céu alto, Sprito Santo, que esclareça e alumee mim que non mereço tanto...” (Dom Duarte), contudo, na "evolução" da língua, foi-se abandonando o emprego das formas tônicas como objeto direto, a não ser quando regidas de preposição a, como no vulgarizado verso de Camões: "Nem ele entende a nós, nem nós a ele.", o caso do objeto direto preposicionado.

Cunha e Cintra (1985) classificam como equívocos e incorreções o uso frequente do ele acusativo, ou seja, ele(s), ela(s) como objeto direto em frases do tipo: "Vi ele". / "Encontrei ele", na fala "vulgar" e "familiar" do Brasil. Os autores destacam ainda que, embora este tipo de construção tenha sido documentado por escritores portugueses dos séculos XIII e XIV, deve ser evitado atualmente. Destarte claramente vemos que os autores censuram o emprego do ele acusativo não por ser um arcaísmo ou atavismo, mas justamente por ser de uso vulgar (ou seja popular) e familiar (não formal).

Bechara (2004), seguindo essa perspectiva, ressalta que “[...] a rigor, o pronome pessoal reto funciona como sujeito e predicativo, enquanto o oblíquo como complemento: Eu saio. / Eu não sou ele. / Eu o vi. / Não lhe respondemos” (BECHARA, 2004, p.173). Entretanto, o pronome pessoal ele (ele acusativo) pode aparecer como objeto direto, no Português Moderno, quando precedido de "todo" ou "só" (adjetivo) ou se dotado de acentuação enfática em prosa ou verso (BECHARA, 2004, p.175). Dessas lições, constatamos que o uso de ele acusativo só é autorizado quando está em situação de ênfase, logo, saindo da Gramática para a Estilística, como podemos ver nos seguintes exemplos: Vi "ele todo" [ele todo, uso enfático opcional = o Sol] abrir-se num leque de plumas. Reconheço "só ele" [só ele, uso enfático opcional] como meu único Salvador.

Notemos que ainda vigora nas gramáticas tradicionais de Cunha; Cintra (1985) e Rocha Lima (2003) o quadro de pronomes pessoais estruturado a partir de três pessoas do 
discurso (eu/tu/ele) com variação de número (nós/vós/eles), o qual diverge da verdadeira realidade do português do Brasil, ignorando outras estratégias comuns à nossa variante.

\section{O ele acusativo nas gramáticas descritivas}

Independente do que a tradição normativa prescreve como "correto", a gramática descritiva busca apresentar os padrões de uso. Segundo Possenti (2005), "[...] é a que orienta o trabalho dos linguistas cuja preocupação é descrever e/ou explicar as línguas tais como elas são faladas" (POSSENTI, 2005, p.17).

A Gramática de Usos do Português (NEVES, 2000), apesar de ser uma gramática de orientação funcionalista, ainda se mantém fiel à tradição gramatical com relação ao uso dos pronomes pessoais na função acusativa. Segundo a autora, “eu, tu, ele/ela" funcionam como sujeito. Mas, além dessas, existem outras formas que exercem outra função, a saber: a) formas átonas (mim, comigo, ti, contigo, si, consigo); e as b) formas tônicas (nós, conosco, vós, convosco, si, consigo). Neves (2000) menciona algumas restrições no uso dos pronomes, como as formas “eu” e "tu”, que são, em princípio, restritas à função de sujeito. Tu, assim como vós, podem, ainda, ser usados como vocativo. E as funções completivas são restritas às formas oblíquas átonas, exceto quando a forma oblíqua átona do pronome pessoal ocorrer como sujeito de uma oração infinitiva, nos seguintes casos: Deixe-me falarlhe de minha felicidade (= deixe que eu fale). / Faça-o subir, tenha a bondade (= faça que ele suba), que constitui objeto direto do verbo junto do qual o pronome átono se coloca como clítico.

Neves (2000, p.457) destaca que, na linguagem falada e também na escrita, ocorrem enunciados com os pronomes pessoais retos na função de objeto direto, como em: "Benê levou 'ele"”. "Quando Ludmila chegou, encontrou 'ele' morto no banheiro. Nunca vi 'ele' assim”. Contudo, a gramática normativa só admite que as formas do pronome pessoal "ele", "nós" e "vós" ocorram como complemento se preposicionadas. Como vimos, a autora reconhece o emprego do ele acusativo sem conferir-lhe valor. 
Passemos agora à Nova Gramática do Português Brasileiro (CASTILHO, 2016), que se caracteriza pelo seu caráter inovador, manifestado no estudo dos pronomes em PB. Em sua gramática, Castilho (2016) faz um percurso histórico do estatuto categorial dos pronomes, desde Apolônio Díscolo até os dias atuais, demonstrando que sempre levaram em conta suas propriedades semânticas, discursivas e gramaticais (sintáticas e morfológicas), acrescentando-se ainda a sua gramaticalização.

Para o autor, os pronomes representam, do ponto de vista semântico-discursivo, (1) as pessoas do discurso (pelo seu caráter dêitico); e (2) a retomada ou antecipação de participantes (pelo seu caráter fórico: anáfora e catáfora). Do ponto de vista gramatical, essa classe exibe as propriedades morfológicas de (i) caso; (ii) pessoa e número; (iii) gênero. Em relação à sintaxe, enfatiza duas relações de base, a de acompanhar ou substituir o substantivo. Segundo ele, a função substitutiva sempre foi lembrada como uma propriedade por excelência dos pronomes, até pela representação do vocábulo pro+nome, "em lugar do substantivo".

De acordo Castilho (2016), os pronomes pessoais são bastante suscetíveis a mudanças, o que se evidencia, sobretudo, em sua modalidade falada, com fortes consequências na estrutura sintática da língua.

Castilho (2016) apresenta um quadro de pronomes pessoais do PB na atualidade, nas duas variedades da língua: o PB formal e o PB informal. Em relação ao ele acusativo, com base na divisão de Castilho (2016), verificamos que a ele se atribui uma nova função, a de indicar o objeto direto (acusativo). Ademais, o ele acusativo é um das formas substitutivas dos oblíquos "o" e "a". No tocante à alteração, o pronome sofreria a mudança de "ele>ei" e de "eles>eis". A esse respeito, Castilho (2016) acrescenta que: i) No uso de "ele/eles" como objeto direto, preservou o nominativo e ganhou o caso acusativo; ii) No desaparecimento das formas "o” e seus alomorfes (lo, no), houve substituição pela forma "ele" no acusativo; e iii) Na atualidade, há concorrência em função do ele acusativo com o lhe acusativo. 
Para Castilho (2016), a perda do clítico o é acompanhada de dois ganhos: "ele" e "lhe", que antes funcionavam como sujeito e objeto indireto, respectivamente, e agora assumem também a função acusativa.

As gramáticas descritivas analisadas vêm contemplar as assertivas que fizemos sobre o ele acusativo e ressaltam a sua importância de estudo. Na presente sincronia e num olhar não normativo, podemos ver que o emprego do ele acusativo impõe-se como realidade não mais vista como nítida separação entre duas variantes do Português, o que poderia em tempo vindouro vir a ter sua construção incorporada ao quadro dos pronomes de nosso vernáculo.

Feito essa sucinta discussão a respeito do pronome ele acusativo nas gramáticas descritivas, sigamos para a análise dos nossos dados.

\section{Análise dos dados}

Servimo-nos dos corpora do PPVC e PCVC para elaboração da amostra da nossa pesquisa, que reúnem, respectivamente, informantes sem ou com até cinco anos de escolaridade e com onze anos ou mais de escolaridade ${ }^{7}$. Inicialmente, selecionamos aleatoriamente os informantes de cada corpus de acordo com a idade, os quais foram distribuídos em três faixas etárias, a saber: (a) faixa I - de 15 a 35 anos; (b) faixa II - de 36 anos a 49 anos; (c) faixa III - de 50 anos em diante. Assim, a nossa amostra foi formada por 24 (vinte e quatro) entrevistas, sendo 12 (doze) informantes do sexo feminino e 12 (doze) do sexo masculino.

Preliminarmente, para descrição e análise dos dados, definimos com variável dependente as seguintes formas de realização do objeto direto anafórico na fala conquistense: a) o uso do clítico acusativo; b) o uso de sintagmas nominais anafóricos; c) o uso do pronome ele acusativo; e d) o uso da categoria vazia (objeto nulo).

${ }^{7}$ No corpus do Português Culto foram considerados os informantes que também já haviam concluído o ensino médio. 
(5) [...] aprender a conviver com os recursos que nós temos né... pra aprender a administrá-“los”. (H.F.D.S, PCVC, II, M) ${ }^{8}$

(6) $[\ldots]$ a tarefa de Perseu é derrotar Hades e ele vai fazê "isso" " ${ }_{4}$ [...] (F.S.L.B, PCVC, $\mathrm{I}, \mathrm{M})$

(7) $[\ldots]$ nem na rua eu dêxo "ele" brinca que eu tem medo de bala perdida [...] (G.N.B, PPVC, I, F)

(8) $[\ldots]$ o médico dela mandô leva $\varnothing$ urgente [...] (J.A.P, PPVC, III, M)

Como variáveis independentes, observamos os seguintes grupos de fatores que podem exercer influência na realização das variantes: traço semântico, tipo de oração, tempo verbal, sexo, faixa etária e escolaridade?

Foram encontradas 275 (duzentas e setenta e cinco) ocorrências de realização do acusativo anafórico. Após análise e rodada dos dados, esse resultado ficou distribuído, percentualmente, em: $2 \%$ do clítico acusativo, 14\% de ocorrências do sintagma nominal, 29\% do objeto nulo ou categoria vazia e 55\% do pronome ele acusativo.

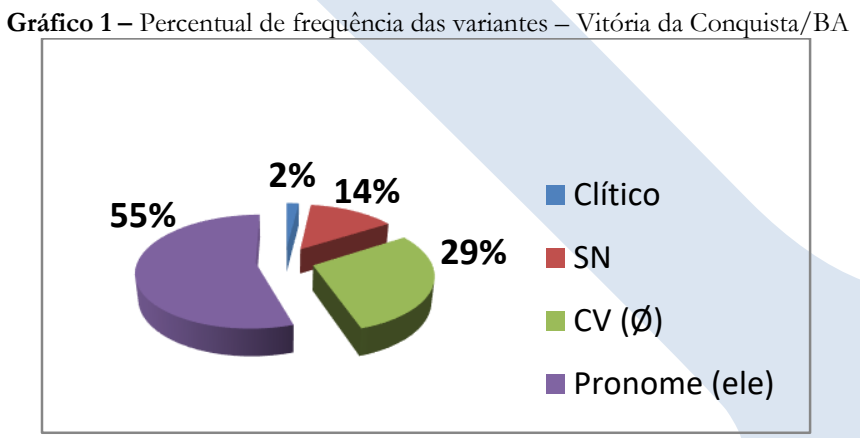

Fonte do autor

\footnotetext{
${ }^{8}$ Os códigos apresentados entre parêntese representam, respectivamente, as iniciais dos nomes dos informantes, seguida da identificação do corpus, da faixa etária e do sexo.

${ }^{4}$ Dentre as poucas ocorrências encontradas nas amostras para o sintagma nominal, consideramos o demonstrativo “isso” para representação dessa variável.

9 Os condicionantes "tipo de oração", "tempo verbal", "sexo", "faixa etária” e "escolaridade” não foram selecionados pelo Programa GoldV arb X.
} 
O uso do Pronome ele acusativo na função de objeto direto foi a variável preferencial pelos falantes conquistenses, com 151 ocorrências, representando 55\%, apresentado no Gráf. 1, seguido da categoria vazia, com 79 ocorrências, e um percentual de $29 \%$.

Apresentamos a seguir que condições têm favorecido o Pronome ele acusativo, já que o emprego da categoria vazia tem se mostrado maior em outras regiões, segundo evidenciam os principais trabalhos acadêmicos sobre a questão (OMENA, 1979; DUARTE, 1986; MONTEIRO, 1994; FREIRE, 2005).

A variável linguística estatisticamente mais relevante selecionada pelo Programa GoldV arb X foi o "Traço Semântico". O uso do Pronome ele acusativo foi fortemente condicionado pelo traço [+ humano] do objeto com $73 \%$ de ocorrências, na amostra da norma culta, e $82 \%$ na norma popular; enquanto que a preferência pela categoria vazia recai sobre os objetos com antecedente [- humano], apresentando um percentual de $74 \%$ e $90 \%$, respectivamente, para a norma culta e popular, quando as rodadas foram realizadas com apenas um valor de aplicação para cada norma, conforme representado na Tab. 1.

Tabela 1 - Traço semântico na realização das variantes no Português culto e popular - Vitória da Conquista (BA)

\begin{tabular}{|l|c|c|c|c|c|c|}
\hline \multirow{2}{*}{ Fatores } & \multicolumn{3}{|c|}{ Norma Culta } & \multicolumn{3}{c|}{ Norma Popular } \\
\cline { 2 - 7 } & Total & $\%$ & $\boldsymbol{P . R}$ & Total & $\%$ & $\boldsymbol{P . R}$ \\
\hline $\begin{array}{l}\text { [+humano] } \\
\text { Pronome ele }\end{array}$ & $50 / 68$ & $73 \%$ &, 657 & $91 / 111$ & $82 \%$ &, 638 \\
\hline $\begin{array}{l}\text { [-humano] Ca- } \\
\text { tegoria vazia }\end{array}$ & $23 / 31$ & $74 \%$ &, 806 & $18 / 20$ & $90 \%$ &, 959 \\
\hline
\end{tabular}

Fonte do autor.

Assim, confirma-se a nossa hipótese para essa variável, uma vez que o Pronome ele acusativo é favorecido com o traço [+humano] e o objeto nulo é favorecido pelo traço [-humano] do antecedente. Assim, imputamos que o traço semântico [_thumano] relaciona-se significativamente com o processo de realização do objeto direto anafórico, de acordo com 
a pessoalidade ou a impessoalidade do seu antecedente, como podemos observar nos enunciados (9) e (10).

(9) [...] ele falou que encontrou "ela", assim com outro home [...] (E.S.B, PPVC, II, F).

(10) Ela sempre quis tocá piano aí ela me incentivo a fazê $\varnothing$, mas quando eu parei ela num ficô chateada nem nada (F.S.L.B, PCVC, I, M).

As demais variáveis linguísticas e extralinguísticas não foram estatisticamente relevantes para o Programa GoldV arb nas rodadas por nós executadas, o que nos leva a não representá-las neste trabalho.

\section{Considerações finais}

No presente artigo, buscamos descrever a história do Pronome ele acusativo no Português do Brasil e seu uso na comunidade de Vitória da Conquista-BA, estabelecendo um cotejo entre as normas popular e culta ao observar as estratégias de realização do objeto direto anafórico.

A rigor, a função de objeto direto é exercida pelos pronomes pessoais átonos (o, a, os, as). No entanto, há algum tempo, reconhece-se um declínio acentuado no uso desses pronomes no PB, que, segundo Menon (1995), na "língua popular, descuidada" o objeto direto passou a ser expresso pelo pronome "ele". Contudo, se observamos bem, iremos verificar que tal uso não se restringe apenas às "classes populares": ele já atingiu pessoas de classes sociais e escolaridade mais elevadas.

Fazendo uma síntese histórica a respeito do emprego do ele acusativo, foi possível chegar a três conclusões: i) não é uma inovação da variante brasileira; contudo, a sua permanência e frequência de uso são traços que podemos relacionar à nossa variante; ii) está 
relacionado aos usos populares (por ser considerado "solecismo"); no entanto, é de emprego comum também em meios não-populares, sendo evitado em situações monitoradas; iii) suscita uma reestruturação do quadro dos pronomes pessoais com base no uso.

Os resultados quantitativos analisados nos permite acurar que, dentre as estratégias de preenchimento do objeto direto anafórico, que têm atuado como variantes nessa função, o Pronome ele acusativo foi a opção preferencial tanto para os falantes do Português Popular como para os do Português Culto da amostra selecionada, seguida da categoria vazia. Já o clítico acusativo e o sintagma nominal foram os menos utilizados.

Do ponto de vista das variáveis linguísticas, a nossa pesquisa revelou que o traço [+humano] do antecedente exerce uma forte tendência na realização da variante do pronome ele acusativo, ao passo que o [-humano] exerceu forte influência no apagamento do objeto, corroborando os resultados encontrados por Omena (1978) e Duarte (1986), sendo esta variável o fator condicionante mais relevante selecionado pelo Programa GoldV arb $X$ nesta pesquisa.

Enfim, esperamos que a nossa pesquisa tenha contribuído com os estudos acerca do acusativo anafórico, na qual expomos uma fotografia sociolinguística do uso do Pronome ele acusativo no vernáculo conquistense, bem como seu percurso histórico.

\title{
THE THIRD-PERSON ACCUSATIVE PRONOUN IN THE HISTORY OF PORTUGUESE
}

\begin{abstract}
This work looks into the strategies of filling the direct anaphoric object in Vitória da Conquista, particularly about the history of the accusative pronoun in the Portuguese vernacular, based on the Variationist Sociolinguistics, in consonance with Socio-history. In this sense, we aim to: (i) reconstruct the history of the third-person accusative pronoun in Brazilian Portuguese, establishing a comparison between popular and formal norms; and (ii) to verify the coexistence of the accusative pronoun in competition with the accusative clitic, in the selected corpora. The data for analysis were extracted from corpora of Popular Portuguese and Formal of Vitória da Conquista, stratified in sex and age group, and submitted to the GoldVarb X Program. The results reveal that the use of the accusative Pronoun tends to be more frequent in linguistic contexts whose antecedent of the object presents the semantic trait [ + human] both between the speakers of the popular norm and the formal norm.
\end{abstract}


KEYWORDS: Accusative anaphoric; Third-person accusative pronoun; Formal and popular Portuguese; Sociolinguistics.

\section{REFERÊNCIAS}

ALMEIDA, Napoleão Mendes de. Gramática metódica da língua portuguesa. 45.ed. São Paulo: Saraiva, 2001.

AMARAL, Amadeu. O dialecto caipira: gramática, vocabulário. São Paulo: Casa Editora O Livro, 1920.

ASSIS, Machado. Dom Casmurro. São Paulo: Melhoramentos, 2010.

BARBOSA, Rui. Réplica. São Paulo: Editora da OAB, 1980.

BECHARA, Evanildo. Moderna Gramática Portuguesa. 37.ed.Rio de Janeiro: Lucerna, 2004.

BUENO, Francisco da Silveira. Estudos de Filologia Portuguêsa. São Paulo: Saraiva, 1967.

BUENO, Francisco da Silveira. Grande Dicionário Etimológico-prosódico da Língua PortuguêsaVocábulos, Expressões da Língua Geral e Científica-sinônimos - Contribuições do TupiGuarani Catedrático de Filologia Portuguêsa da Universidade de S. Paulo. 6.v. 2 Tiragem. São Paulo: Edição Saraiva, 1968. p. 3215.

CAMARA Jr, Joaquim Mattoso. Problemas de Linguistica Descritiva. 3.ed. São Paulo: Vozes, 1972.

. Dispersos de J. Mattoso Câmara Jr. Seleção e Introdução por Carlos Eduardo Falcão Uchôa. 2.ed. Rio de Janeiro: Editora da Fundação Getúlio Vargas, 1975 [1957].

. História e Estrutura da Lingua Portuguesa. 3.ed. Rio de Janeiro: Padrão - Livraria Editora Ltda., 1979 [1975].

. Dicionário de Lingüistica e Gramática. 11.ed. Petrópolis: Vozes, 1984.

CASTILHO, Ataliba T. de. Nova Gramática do Português Brasileiro. São Paulo: Contexto, 2016.

COUTINHO, Ismael de Lima. Gramática Histórica. Rio de Janeiro: Imperial Novo, 2011.

CUNHA, Celso; CINTRA, Lindley. Nova gramática do Português Contemporâneo. 2.ed. Rio de Janeiro: Nova Fronteira, 1985.

DALGADO, Sebastião Rodolfo. Estudos sobre os crioulos indo-europeus. Lisboa: Comissão para as comemorações dos descobrimentos portugueses, 1998. 
DUARTE, Maria Eugênia Lamoglia. Variação e sintaxe: clítico acusativo, pronome lexical e categoria vazia no português do Brasil, 1986, 73 f., (Dissertação de Mestrado em Ciências - Linguística Aplicada ao Ensino de Línguas), Pontifícia Universidade Católica de São Paulo, São Paulo.

ELIA, Silvio. A unidade linguística do Brasil: condicionamentos geo-econômicos. Rio de Janeiro: Padrão, 1979.

FIGUEIREDO, Cândido. O que se não deve dizerer. Lisboa: Clássica, 1912.

FREIRE, Gilson Costa. A realização do acusativo e do dativo anafóricos de terceira pessoa na escrita brasileira e lusitana, 2005, 204f., (Tese de Doutorado em Língua Portuguesa), Faculdade de Letras, Universidade Federal do Rio de Janeiro, Rio de Janeiro.

HOUAISS, Antônio; VILLAR, Mauro de Salles. Dicionário Houaiss da Língua Portuguesa, elaborado pelo Instituto Antônio Houaiss de Lexicografia e Banco de Dados da Língua Portuguesa S/C Ltda. 4.ed. Rio de Janeiro: Objetiva, 2000. p. 1560-1561.

LABOV, William. Sociolinguistic Patterns. Philadelphia: University of Pennsylvania Press, 1972.

. Padrões Sociolingüisticos. Trad. de M. Bagno; M. M. P. Scherre; C. R. Cardoso. São Paulo: Parábola Editorial, 2008 [1972].

MARROQUIM, Mário. A lingua do Nordeste (Alagoas e Pernambuco). São Paulo: Cia. Editora Nacional, 1934.

MENON, Odete Pereira da Silva. O Sistema Pronominal do Português do Brasil. Revista Letras. Curitiba: Editora da UFPR, v.44, 1995, p.91-106.

MONTEIRO, José Lemos. Pronomes Pessoais: subsidios para uma gramática do português do Brasil. Fortaleza: Edições UFC, 1994.

NEVES, Maria Helena Moura. Gramática de Usos do Português. 6.reimpr. São Paulo: Editora UNESP, 2000.

NUNES, José Joaquim. Compêndio de Gramática Histórica Portuguesa (Fonética e Morfologia). 8.ed. Lisboa: Livraria Clássica Editora, 1975 [1910].

OMENA, Nelize Pires de. Pronome pessoal de terceira pessoa: suas formas variantes em função acusativa, 1978, 138 f., (Dissertação de Mestrado em Língua Portuguesa), Pontifícia Universidade Católica do Rio de Janeiro, Rio de Janeiro.

PALHANO, Herbert. O português popular do Brasil. São Paulo: FTD, 1958.

POSSENTI, Sírio. Por que (não) ensinar gramática na escola. Campinas: Mercado das Letras, 2005 [1996]. 
ROCHA LIMA. Gramática Normativa da Lingua Portuguesa. 43.ed. Rio de Janeiro: Editora José Olympio, 2003.

ROMAINE, Suzanne. Socio-Historical Linguistics: its Status and Methodology. New York: Cambridge University Press, 1982.

SAID ALI, Manuel. Gramática Secundária e Gramática Histórica da Lingua Portuguesa. 3.ed. Brasília: Editôra Universidade de Brasília, 1964.

XXXX. A concordância verbal de terceira pessoa do plural no português popular do Brasil: um panorama sociolinguístico de três comunidades do interior do estado da Babia. 2005. $323 \mathrm{f}$. (Tese) Doutorado em Letras) - Instituto de Letras, Universidade Federal da Bahia, Salvador, 2005.

SILVA NETO, Serafim da. Introdução ao estudo da Lingua Portuguesa no Brasil. 5.ed. Rio de Janeiro: Presença, 1986 [1950].

SILVEIRA, Sousa da. Lições de Português. 9.ed. Rio de Janeiro: Presença; Brasília: INL, 1983 [1952].

VASCONCELOS, José Leite. Notas filológicas. Lisboa: Edição Revista de Portugal, 1912.

Recebido em: 14/08/2018.

Aprovado em: 19/12/218. 